\title{
First Steps towards the Emergence of Emotions in Interaction Design
}

\author{
Lingxue Yang, ${ }^{1,}$, Pierre Morizet-Mahoudeaux ${ }^{1}$, Anne Guénand ${ }^{2}$, Assia Mouloudi ${ }^{3}$ \\ ${ }^{1}$ Sorbonne-Universités, Université de Technologie de Compiègne \\ UMR CNRS 7253 HEUDIASYC \\ CS 60319, 60203 Compiègne-Cedex, France \\ lingxue.yang@sap.com; pierre.morizet@utc.fr \\ ${ }^{2}$ Sorbonne-Universités, Université de Technologie de Compiègne \\ Laboratoire COSTECH \\ CS 60319, 60203 Compiègne-Cedex, France \\ anne.guenand@utc.fr, \\ ${ }^{3}$ SAP, 35, rue d'Alsace, 75098 Paris, France \\ lingxue.yang@sap.com; assia.mouloudi@sap.com
}

\section{Extended Abstract}

As we enter in a new era of Big Data, the volume of data raises new challenges in Business Intelligence (BI). Currently, to make a proper decision, users must interact with complex massive data through sophisticated BI software. In addition, the rise of technology and fierce marketing competition increasingly requires taking into account the user's subjective part of the needs, including emotion. Although this study focuses on BI tools, we take the general view of the context of use, and we aim to qualify interaction. Our objective is to study the various factors that may make emerging emotions in the scope of interactive tasks, and to improve their consideration in the design of users centred interactive information systems.

Based on the cognitive theory of emotions [1] and C.Lenay et al.'s sensori-motor coupling [2], we consider that emotions emerge from the appraisal of the dynamic user interaction and the perception of the system through this interaction. This appraisal is influenced by the dynamic context, such as user's expectation, goals and needs, knowledge and experience, etc. We focus on the design of interactive applications, which provides users emotional experience.

From this perspective, we first studied the design principles behind interface and interaction design. Then we developed a test to evaluate the user interface and interaction semantically referring to the sensory evaluation proposed by Lefebvre et al. in [3]. The test was carried out with 8 expert designers on a sample of 4 kinds of interactive tools covering different types of interaction. The objective was to extract the elements, which can characterize the interaction of applications from a design professional perspective.

We defined a scenario that the experts should follow to express their feeling about the extent to which the 4 interactive tools meet interactive tasks requirements. From this, we collected 149 words, which were freely proposed by the expert designers, and classified them into 24 categories. Then, we analysed these categories to exhibit the characteristics that were the most frequently used and shared by the expert designers to evaluate the interaction qualities of the applications. In addition, we picked out the emotional words used by the experts and then divided them into different causes - expectation, interaction and impact. This gave us insights to define a questionnaire scope for future experiments and classes of criteria that can be used to design an application from through which the user will engage and feel emotions.

A further study will be to propose a vocabulary of evaluation of the design and to conduct an experimentation to measure positive experience that we will transform into a model for the design interactive BI applications.

\section{References}

[1] P. Desmet, "A Multilayered Model of Product Emotion,” The Design Journal, vol. 6, pp. 1-13, 2003.

[2] C. Lenay, I. Thouvenin, A. Guénand, O. Gapenne, J. Stewart, and B. Maillet, "Designing the ground for pleasurable experience," in Proceedings of the 2007 Conference on Designing Pleasurable Products and Interfaces DPPI 07, 2007.

[3] A. Lefebvre and J. Bassereau, "L'analyse sensorielle, une méthode de mesure au service des acteurs de la conception: ses avantages, ses limites, ses voies d'amélioration. Application aux emballages," in 10 ième Séminaire CONFERE, 34 Juillet 2003, Belfort - France, pp. 3-11. 